$128.2352185 \% \cdot 2$

Serial No. 2185

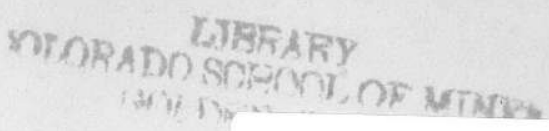

metadc1393302

\title{
REPORTS OF INVESTIGATIONS
}

BURFAU OF MINES - - NOVEMBER, 1920 - - DEPARTMENT OF INTERIOR

\section{ANALYSFS OF AIR FROM BURNING BUILDINGS .}

By S. H. Katz (Assistant physical chemist, Bureau of Mines).

At the annual meeting of the Intemational Association of Fire Engineers at Kansas City, Mo., in June, 1919, the Bureau of Mines offered to cooperate with municipal fire departments for the purpose of obtaining information regarding composition of the air in burning buildings. (Katz, S. H., Statement made at Convention of International Assoc. of Fire Engineers: Fire and Water Eng., vol. 66, July 16, 1919, pp. 129-30, also Fireman's Herald, vol. 78, July 12, 1э19, pp. 48.) The gas-mask laboratory of the Bureau's experiment station at Pittsburgh sent vacuun bottles for taking samples to fire chiefs in twenty-five cities, who had signified their intention to aid in this work. It was hoped to obtain one hundred or more samples, because statistics in quantity are necessary for drawing reliable conclusions concerning the likelihoods of encountering irrespirable gas in burning buildings. Thus far, eleven samples have been received by the laboratoy. Results of analyses and pertinent data regarding these samples are given in the accompanying table.

Eight of the eleven samples contained no carbon monoxide; seven of the eight were taken above the ground level and one below ground. One sample taken above ground contained 0.03 per cent carbon monoxide, and this quantity is not dangerous to breathe for a limited time. Of the three samoies taken below ground, one contained no carbon monoxide; the other two contained 0.10 and 0.35 per cent, respectively. This indicates that in a burning building, the hazard from carbon monoxide is much greater below the ground level. The cause undoubtedly lies in the poorer ventilation that is usually found in cellars or basements. Abundance of ventilation provides the necessary air for complete combustion, or if incomplete combustion does occur, the carbon monoxide generated by the fire is greatly diluted with fresh air and swept away by the current. It may be noted that the highest proportion of carbon monoxide was found in a cellar where a fire was burning among piled cases. The difficult access of air to the buining parts facilitated the formation and liberation of carbon monoxide. The smoke here was very light and no difficulty was experienced in breathing. Some of the air containing dense smoke showed little change from nomal air by analysis. Thus the density of smoke or the irritation and difficulty it causes in breathing are no indication of the presence of poisonous gas. None of the samples shows inportant deficiencies in oxygen.

It is hoped that in time more air samples from burning buildings will be analyzed in order to extend the little information given here. Especial credit is due the men who, in the turmoil and anxiety that accompanies efforts to subdue fires, and with possible danger to themselves, have been ablo to take the samples. - U. S. Bureau of Mines, Reports of Investigations. 
DATA ON SAMPLES OF ATNOSPHERES FROM BURNING BUILDINGS.

(Norial air contains carbon dioxide, 0.03 par cent; oxycen, 21.93 jer cent; nitrogon, 79.04 per cent by volure.)



